\title{
“Ölümle Yaşam Arasında” Filminin İncelenmesi: Kurtarma Fantezisi ve Ahlâki Mazoşizm
}

\author{
Beyza Ünal \\ Orta Doğu Teknik Üniversitesi
}

\begin{abstract}
Özet
"Ölümle Yaşam Arasında" (The Life of David Gale, Alan Parker, 2003) filmi, ölüm cezası karşıtı bir toplulukta görev alan bir felsefe profesörünün, aynı toplulukta çalıştığı bir kadın arkadaşına tecavüz etmek ve onu öldürmekle suçlanması nedeniyle ölüm cezası almasını ve infazından önce üç gün boyunca bir gazeteciye verdiği röportajla duruma neden olan olayları anlatmasını işlemektedir. Profesörün ve arkadaşının yaptığı seçimlerin temelinde, yaşadıkları bazı haksızlıklar nedeniyle sahip oldukları ve değer verdikleri şeyleri kaybetmeleri sonucu alevlenen kurtarma fantezilerinin ve ahlâki mazoşistik kişilik yapısının yer aldığı ve bunların narsistik ihtiyaçlarla beslendiği dikkat çekmektedir. Profesörün ve arkadașının, profesörün ölüm cezası almasına neden olacak șekilde kurguladığı senaryo ise, onları içinde bulundukları döngüden kurtarmaktan ziyade, temeldeki özelliklerini destekleyen bir özellik taşımaktadır. Her iki kişi de, içinde bulundukları acıyı kontrol edebilmek ve başkalarıyla da bu yolla iletişim kurabilmek amacıyla bir tekrarlama kompülsiyonu içinde davranmakta ve ölüm cezasının anlamsızlığını göstererek elde etmeyi amaçladıkları hazzı ve mutluluğu elde etmelerine rağmen, kendilerinin bu zevki yaşamalarına engel olarak benzer bir mazoşist döngüyü sürdürmektedirler.
\end{abstract}

Anahtar Kelimeler: Ahlâki mazoşizm, kurtarma fantezisi, narsisizm, tekrarlama kompülsiyonu. 


\section{“Ölümle Yaşam Arasında” Filminin İncelenmesi: Kurtarma Fantezisi ve Ahlâki Mazoşizm}

Yönetmenliğini Alan Parker'ın yaptığı ve başrollerini Kevin Spacey ile Kate Winslet'ın paylaştığı, 2003 yapımı “Ölümle Yaşam Arasında" (The Life of David Gale) filminde, ölüm cezası karşı1tı aktivist bir toplulukta görev alan bir felsefe profesörü (David Gale), tecavüz ve cinayet suçlamalarıyla ölüm cezasına mahkûm edilmiştir. Filmde, geri dönüş tekniğinden yararlanılarak, David'in infazından önceki üç gün boyunca bir gazeteciye (Bitsey Bloom) kendi isteğiyle verdiği röportaj üzerinden bu suçlamaların perde arkası gösterilmektedir. David, ölüm cezasına sahip bir yarg1 sisteminin yanlış işleme ihtimalini ve masum bir insanın ölümüne neden olabileceğini göstermek adına, ölüm cezası karşıtı bir toplulukta görev alan Constance Harraway ile birlikte bir senaryo kurgulamıştır. Bu senaryonun sonucunda, David, Constance'a tecavüz etme ve onu öldürme suçlarından yargılanmış ve dolayısıyla kendi hayatını savunduğu fikirler uğruna feda etmiştir.

David, Bitsey’e, röportajın, hayatının nasıl sona erdiği kadar yaptığı seçimlerle de anılması amacıyla yapıldığını söyleyerek, olayların başlangıç noktası olarak gördüğü bir dersinden bahseder. David, bu derste arzunun devam etmesi için, eksikliğin var olması gerektiğini; arzulanan şeye erişildiği an arzunun yok olacağını ve bu nedenle fantezilerin gerçekdışı olması gerektiğini Lacancı bir bakış açısıyla savunmaktadır. Bununla birlikte, hayatın değerinin arzulara ne kadar ulaşıldığıyla değil, diğer insanların yaşamlarına samimiyetle ve özveriyle ne kadar değer verildiğiyle ölçüleceğini ifade etmektedir. Ancak, David bu fakirleri savunmasına rağmen, eşi tarafından aldatıldığını düşündüğünü söylediği bir partide, dersinde zorluk yaşayan ve okuldan atıldığını öğrendiği bir öğrencisiyle cinsel birliktelik yaşar ve arzusunun peşinden gider. Ertesi gün, tam da ifade ettiği gibi, arzusuna ulaşmasının kendisini mutlu etmediğini fark eder. Bu nedenle, aynı gün valiyle birlikte katıldığ ölüm cezasının tartışıldığı bir programda, Constance'ın uyarılarına rağmen öfkesine hâkim olamayarak, konuyu ölüm cezası almış masum bir kişiyi göstermesinin isteneceği bir noktaya getirir ve tartışmanın kendi aleyhine dönmesine neden olur. Birlikte çalıştığı arkadaşı Constance, David'in tartışmayı bu noktaya getirmesinin birlikte çalıştıkları topluluğa zarar verdiğini öfkeyle ifade eder. David, bu olayın hemen arkasından bir gece önce cinsel birliktelik yaşadığı öğrencisinin kendisine yönelik suç duyurusunda bulunduğunu öğrenir ve gözaltına alınır. Bu haksız tecavüz suçlaması, ailesini, evini ve işini kaybetmesine, topluluktaki saygınlığının azalmasına ve topluluktan dışlanmasına neden olur. Bu süreçte, farklı üniversitelerde iş aramaya başlar. Aldığı olumsuz sonuçlar ise, gittikçe daha fazla alkol kullanmasına ve durumun daha da kötüleşmesine neden olur. Bir süre sonra, bir şeyleri düzeltebilmek adına, alkol bağımlılığına yönelik bir grup terapisine katılır.

Öte yandan, David, hayatındaki tek dostu olarak gördüğü Constance'ın lösemi hastalığının son evresinde olduğunu öğrenir. Constance, bir infaza daha engel olamamanın üzüntüsü içinde olduğu bir gece, David'e hayatına dair pişmanlıklarından birinin az sayıda seks yapması olduğunu söyler. O gece David ve Constance birlikte olurlar. Ertesi gün Constance kendi evinde başına bir poşet geçirilmiş, elleri arkadan kelepçelenmiş ve anahtar kendisine yutturulmuş halde, üzerinde David'e ait spermle çırılçıplak yere yatmış ve ölü bir şekilde bulunur; dahası Constance'a dönük bir kamera, olayın kayda alınmış olduğunu göstermektedir. David, Bitsey’e bütün bu olanların kendisine hazırlanmış bir tuzak olduğunu ve Constance'a çok yakın bir erkeğin (Dusty Wright) 
kendisini kıskandığı için böyle bir suçu üzerine attığını anlatır. David'in infazının hemen öncesinde Bitsey bu bilgiyi doğrulayan ve Dusty'nin olay yerinde olduğunu gösteren bir kaset bulur; ancak kaseti gerekli yere yetiştiremediği için infaza engel olamaz. Yine de David'in masum olduğu ve sistemin yanlış işleme ve masumları cezalandırma olasılığının bulunduğu kamuoyuna duyurulur. Oysa bir süre sonra, Bitsey’e gönderilen bir başka kaset, Constance'ın öldürülmediğini ama intihar ettiğini ve Dusty'nin ve David'in yalnızca arkadaşlarının intiharını izlediğini; dolayısıyla David'in kendisine yapılacak suçlamaların ve verilecek cezanın bilincinde olduğunu göstermektedir. Bu yolla David, kendi hayatını sonlandırmayı göze alarak, ölüm cezasının kaldırılmasını sağlamak ve başka insanların hayatlarına verdiği değeri göstermek istemiştir. David'in, Bitsey'le yaptığı röportajın amacıyla ilgili belirttiklerine paralel olarak, ölüm cezasını almaya yönelik yaptığı seçimler kurtarma fantezisi [rescue fantasy] ve ahlâki mazoşizm [moral masochism] çerçevesinde ele alınacaktır.

Freud (1910; akt. Esman, 1987), "kurtarma fantezisi” terimini ilk olarak, erkeğin, bilinçdışında kadını ahlaksızlıktan kurtarmasıyla açıklamış ve bunun, başka bir erkeğe cinsel olarak bağlı annenin kurtarılmasını temsil ettiğini belirtmiştir. Bu sayede, kurtarma fantezileri, simgesel düzeyde, ödipal babaya karşı çıkarak onunla ödeşmeyi ve annenin sevgisinin elde edilmesini sağlamaktadır. Bu açıklamayı izleyen tartışmalarda ise, kurtarma fantezisinin, hâlihazırda var olan öldürme isteğinin neden olduğu suçluluk ile ortaya çıkan karşıt tepki oluşturma savunması ile alakalı olabileceği ve aynı zamanda bir yapıp bozma işlevi görebileceği üzerinde durulmuş (Gillman, 1992) ve ölümsüzlük tasarımlarıyla alakalı çözülmemiş çocuksu tümgüçlü bir bileşen içerdiği ve narsistik onarımı sağlamak adına ortaya çıkabileceği belirtilmiştir. Bu tür fantezilerde, bireyler kendilerini hem etken bir şekilde kurtaran hem de edilgen bir şekilde kurtarılan olarak konumlandırabilir ve hayatlarını bu şekilde yönlendirebilirler. Bu durum özellikle terapötik ilişkide hem terapist hem de hasta tarafından deneyimlenebilmekte; terapist danışanına yardım ederken, kendi yaralarının da iyileşmesini, hasta ise kurtarıldıktan sonra güçsüz veya çaresiz algılayabildiği terapistini kurtarmayı arzulamaktadır (Sabbadini, 2003).

Kurtarma fantezisiyle ilgili bilgiler göz önünde bulundurulduğunda, "Ölümle Yaşam Arasında"nın, birçok açıdan bu konunun işlendiği bir film olduğu görülmektedir. Örneğin, David ve Constance, üst düzey görevlilerinden oldukları topluluklarında, ölüm cezası almış ve infaz edilmeyi bekleyen mahkûmların hayatlarını kurtarmayla ilgili yoğun bir şekilde uğraş vermektedirler. Ancak, ölüm cezası almış mahkûmların fotoğraflarının asılı olduğu ve infazı durdurulamayan her mahkûmun üzerine çarpı işareti atılan duvardan, kurtarabilmeyi başardıkları bir mahkûmun bulunmadığı; valiyle yapılan tartışma programından ise hükümetin bu konuya olumsuz yaklaştığı ve ölüm cezalarıyla ilgili bir değişikliğe gitmeyeceği anlaşılmaktadır. David ve Constance'ın her kurtarma girişimi başarısızlıkla sonuçlanmakta ve her defasında yasa karşısındaki güçsüzlükleri kendilerine hatırlatılmaktadır. Dolayısıyla, her ikisi de ödipal babayı alt edememiş ve onunla ödeşememişlerdir. Öte yandan, valiyle yapılan tartışma programında David'in öfkesini kontrol edemeyerek konuyu kendi aleyhine döndürmesi, özyıkıcı davranışların kurtarma motifiyle birlikte var olabileceğini düşündürmektedir. Bu durum, David'in kurtarma fantezisini gerçekleştirmek üzereyken, birincil süreçlerin işlemesiyle birlikte 'haz ilkesi'ne göre hareket etmeye başlaması ve hazzı ertelemekte zorlanmasıyla açıklanabilir. Bir diğer psikanalitik açıklama ise, kurtarma fantezisinde görülen bu tarz bir özyıkıcı davranışın, yasaya ve yasayı temsil edenlere karşı çıkmaktan temellenen bilinçdışı suçluluk duygularıyla ortaya çıkabileceğine odaklanmaktadır (Sabbadini, 2003). Sonuç olarak, süperego faaliyetleri, kurtarma fantezisinin gerçekleşmesine izin vermeyerek, David'in tümgüçlülük ihtiyaçlarının karşılanmasına engel olmuş ve onun narsistik bir kırılma yaşamasına neden olmuştur. Tartışma programının hemen arkasından gelen okuldan atılan öğrenciye tecavüz suçlaması ise, hayatında değer verdiği ve değer 
gördüğü her şeyi kaybetmesine neden olur; bu durum adeta David'in yaşadığı içsel kırılmanın görsel bir temsilidir.

David, kendini ancak löseminin son evresinde bulunması nedeniyle benzer bir kırılma yaşayan Constance'ın yanında huzurlu ve güvende hissetmektedir. Tamamıyla özyıkıcı özellikler içeren sonuncu kurtarma fantezisi ise, Constance'ın bu kırılmayla birlikte intihar etmeye karar vermesi üzerine kurulmuştur. Constance'ın intiharı, kendisini acı içinde ve çaresiz bir durumda bırakacak şekilde planlanmış; içgüdüsel olarak kendisini kurtarması bile engellenmiştir. Constance, kendi başına taktığı poşeti bantlar, ellerini arkadan kelepçeler ve anahtarı yutarken, tek kurtuluşunun olayı izleyen Dusty ve David'in poşeti yırtmasıyla olabileceğinin farkındadır; bu sefer, kurtarma fantezisinin edilgen tarafinda kurtarılmayı arzulayan kişi olarak bulunacaktır. Öte yandan, başkası tarafından kurtarılmadığı takdirde, acı ve çaresizlik içindeki ölümü, David'in suçlanmasına neden olacak ve ölüm cezasının masum kişilere de verilebileceğinin kanıtını oluşturarak çektiği acıyı haklı çıkaracak bir amacı gerçekleştirecektir. Bu senaryo içerisinde, David de benzer bir rol üstlenerek, infazının sonrasına kadar bu gerçeği saklayacak ve her şeyin infazından sonra açıklanmasını sağlayacaktır.

Ahlâki mazoşizm, Freud (1924; akt. McWilliams, 2010) tarafından, cinsel mazoşizm ile bir amaç uğruna yaşanan acı çekme örüntüsünü ayrıştırmak amacıyla ortaya atılmış; kendine zarar veren ve kendini değersizleştiren tutumları bulunan ve diğer kişilere kendi çektikleri acılar yoluyla acı vermeye yönelik arzular taşıyan ve bu örüntüde davranan kişilerin mazoşistik kişilik özellikleri taşıdıkları ifade edilmiştir (Reich, 1933). Freud (1920; akt. Cooper, 1988), aşağılanma ve acı çekme arayışı üzerine bir kişilik oluşturan mazoşistik kişilerde var olan bilinçdışı suçluluk duygularının, katı bir süperego faaliyetiyle birlikte, cezalandırılmaya yönelik bir ihtiyaç ortaya çıkardığını ve bu kişiler için acı çekmenin bir zevk olmaktan ziyade, zevk için bir koşul haline geldiğini belirtmiştir. Ayrıca, bu kişilerin içinde bulundukları acı verici duruma, gelecekte yaşanacak daha fazla bir iyilik hâlinin umuduyla katlandıkları vurgulanmıştır. Bir diğer deyişle, mazoşistik ya da kendi aleyhine işleyen kişilikler, içinde bulundukları acının, çektikleri acıyı haklı çıkaracak bir amacı gerçekleştirdiğine ya da kendilerini çok daha fazla acı verici diğer ihtimallerden uzak tuttuğuna inanırlar. Bu sayede, acı verici bir durumu hâkimiyetleri altına almaya ve yaşadıkları acının yerini ve zamanını kendileri seçmeye çalışırlar. Bu nedenle, kendilerini acı içinde bırakacak yeni durumlar yaratma ihtiyacı duyabilir ve bir tekrarlama kompülsiyonu [repetition compulsion] içinde bulunabilirler (McWilliams, 2010; Kernberg, 2009).

Filmde, David'in tecavüz suçlamasıyla her şeyini kaybetmesinin sonucu yaşadığ 1 kırılmanın, alkolü kötüye kullanmaya başlamasına neden olduğu görülmektedir. Bir gece, yüksek dozda alkol almış bir şekilde sokakta gezerken, yüksek bir sesle Sokrates'in ölüm cezasına çarptırıldığından ve kendi cezasını seçme hakkı tanındığında ise, yargıçları öfkelendirecek bir miktarı önererek kendisinin ölümünü istemelerine neden olduğundan bahsetmektedir. David, bu monolog esnasında, üstüne basa basa Sokrates’in kendi ölümüne neden olmasını anlamsız bulduğunu ifade etmektedir. Oysa David ve Constance, yaşadıklarının sonunda, acı çekmenin ve ölmenin kendilerinden daha büyük bir amacı gerçekleştireceğine ve onları, sağlığın ya da saygınlığın kaybı nedeniyle yaşayacakları acıdan uzaklaştıracağına inanırlar. Bu, aynı zamanda, her şey açıklandığında David'in adının temize çıkmasını sağlayacak bir plandır; ancak David, hem birlikte olduğu öğrencisi tarafindan kendisine gönderilen özür içerikli kartpostalı hem de masumiyetini kanıtlayan kaseti ölümünden sonra ortaya çıkacak şekilde ayarlamıştır. Bu durum, David'in içinde bulunduğu acı verici durumları değiştirmeye yönelik fursatları olmasına rağmen, onları değerlendirme ihtiyacı içinde bulunmadığını göstermektedir. Bu nedenle, haksızlık ve acı içinde bulunacağı bir ortamın yaratılmasında kendisinin de pay sahibi olduğu ve önceden ayarlamış olduğu acı sonuyla, başkalarına kendi ölümünün haksızlığını göstererek, onlara acı vermeye yönelik arzusunu gerçekleştirdiği düşünülmektedir. David ve Constance, bu sayede 
ahlâki bir zafer elde etmiş, yaşamları boyunca başarıya ulaşamadan göstermeye çalıştıkları yargı sisteminin açığını kendi ölümleriyle gösterebilmiş; ancak, seçtikleri yolla birlikte bunun vereceği gururu yaşamaktan kendilerini alıkoymuşlardır.

Mazoşizmin bağlı olduğu ego savunmaları incelendiğinde, mazoşizmin ölüm içgüdüsünün bir bileşeni olduğu ve sadistik ya da saldırgan güdülerin içe döndüğü; tekrarlama kompülsiyonunın da eyleme-koyma savunması sonucunda ortaya çıkabileceği açıklanmaktadır (Freud, 1920; akt. Cooper, 1988). Benzer örüntülere sahip kişilerde sıklıkla karşılaşılan diğer savunmalar ise inkâr, içe-atma, ilkel idealizasyon ve özellikle ahlâki mazoşistlerin başvurduğu, ahlâksallaştırmadır. Bu sayede kişiler, acı çektiklerinin ve suiistimal edildiklerinin farkında olmalarına rağmen yaşadıkları rahatsızlık duygusunu inkâr edebilir, kendisini aşağılayan ve değersizleştiren diğerleriyle özdeşleşebilir, bağlandıkları kişilerin tümgüçlü olduklarını algılayabilir ve bu nedenle, onlarla iç içe geçme eğiliminde olabilirler (McWilliams, 2010). Öte yandan, ilkel idealizasyon beraberinde değersizleştirmeyi getirir ve kişilerin hayal kırıklığ1 yaşama olasılığı artar. Bu durum Cooper (1988)'ın, mazoşizm ve narsisizmin gelişim ve klinik görünüm açısından iç içe oldukları ve tek başlarına gözükmedikleri vurgusuyla paralellik göstermektedir. Özellikle ahlâki mazoşistik kişilik yapısı gösteren kişiler, ilişkide olduğu diğer kişilerle ilgilenmekten ziyade, kendilerinin ezici durumlar karşısındaki haklılık ve çaresizliklerini öne çıkarır ve bunlara karşılık olarak, karşılanması güç isteklerde bulunurlar. Bu "haksılılı toplama" [injustice collecting] örüntüsüyle birlikte, ilişkide olduğu kişilerde büyüklenmeci ve öfkeli bir tutumlarının olduğu izlenimi bırakırlar. Bu izlenim, narsistik bir şekilde özsaygılarını desteklemelerine neden olur ve narsistik-mazoşistik kişilik yapısının temelini oluşturur (Schafer, 1984; Cooper, 1988). Bu yapıya sahip hastalar, terapi sürecinde, ödipal dönem öncesi anneyle yaşantıların aktarımı sonucu, terapisti kendilerinkinden farklı düşünce, duygu veya davranışa sahip olmayan bir uzantı gibi görme eğiliminde olurlar. Böylece, terapist tümgüçlü ve tamamen verici bir "ideal anne" olarak algılanır ve terapistin gösterdiği kabulle birlikte, hastalar, sonunda "gerçek sevgi” yi bulduğuna inanırlar. Ancak, kendileriyle terapist arasındaki farklılıkların varlığını algıladıklarında, çok büyük bir hayal kırıklığıyla, onu yine tümgüçlü fakat zalim bir anne olarak görmeye başlarlar (Durkin, 1957). Kendi ihtiyaçları ve isteklerinin, karşıdaki kişi tarafından (anne/terapist/diğer yakınlar) kasıtlı olarak karşılanmadığına dair ortaya çıkan bu aktarımın, narsistik-mazoşistik döngünün devamını sağladığı düşünülmektedir. Bu durumda, mazoşizm bir amaç olmaktan ziyade, öfkenin ve narsistik ihtiyaçların korunduğu ve devam ettirildiği bir döngünün aracı haline gelir. Asıl amaç ise, ancak mazoşizmle elde edilen bilinçdışı kazançların incelenmesi sayesinde anlaşılabilir (Brown ve Nyswander, 2010).

Ahlâken yapmak zorunda hissettiği şeyler için yollar bulmalarını sağlayan ahlâksallaştırma savunmasını sıklıkla kullanan ahlâki mazoşistik kişilik yapısına sahip kişiler, herhangi bir durumda başkalarının suçlu olduğunu göstermeyle ve ahlâki bir zafer kazanmayla o kadar ilgili olabilirler ki, adaletsizlikleri ortadan kaldırmak yerine, yeni adaletsizlikler yaratmayı ve onları sürdürmeyi tercih edebilirler. Dolayısıyla, mazoşistik kişiler, kendilerinin çaresizliğini dinleyecek ve onlara yalnızca acı çektikleri için ilgi göstereceklerine inandıkları kişiler arayabilir ve onları kurtarılmaları gerektiğine ve kurtarılmayı hak ettiklerine inandırmaya çalışabilirler. Bu durumda, ilişki, ilişkinin bulunduğu noktaya bağlı olarak değişkenlik göstermekle birlikte, mazoşistik kişiyle aşırı şekilde ilgilenme (karşı-mazoşizm) veya reddedici ve cezalandırıcı bir tutumda olma (sadizm) şeklinde; çoğu zaman ise her ikisinin de yaşandığı bir şekilde devam eder (McWilliams, 2010).

David, bir haksızlığa uğrayıp her şeyini kaybettikten sonra, bu haksızlığı ortaya çıkararak yaşadığı adaletsiz durumu çözmekten ziyade, içinde bulunduğu haksız durumu devam ettirerek, sahip olduğu hayatını geri almak için başka üniversitelerde işe girmeye çalışmıştır. Ancak, bu, mazoşistik kişilik yapısında sıklıkla görülen karşılanması güç isteklerde bulunma ve sonucunda 
yaşanan haksızlık toplama örüntüsünü düşündüren bir davranış olmakla birlikte, David'in, içinde bulunduğu acı verici durumu pekiştirme yoluyla kontrol altına almaya çalıştığı ve bir tekrarlama kompülsiyonu içinde olduğu şeklinde yorumlanabilir. İş arama süreciyle birlikte, alkol bağımlılı̆̆ tedavisi için grup terapisine başlaması da David'in acı çektiği için ilgilenildiği bir çevre bulma ve onlara kendisinin kurtarılması gereken biri olduğunu inandırma çabalarını göstermektedir. Bütün bunlar, aynı zamanda özsaygısını oldukça zedeleyici deneyimler olmakta ve bununla baş edebilmek adına narsistik bir ihtiyaçla, kendisine evini açan Constance ile birlikte tamamen özyıkıcı bir senaryoyu işletme kararı almalarıyla sonuçlanmaktadır. Bu kararın alınmasında, mazoşistik kişilerle olan iletişimde oluşan karşı-mazoşizmin ve sadizmin etkili olmuş olabileceği düşünülmektedir. Hem David hem Constance, yargı sisteminin yanlışlığını göstermenin yanında, kendilerinin ve birbirlerinin çektiği acıları sonlandırmak adına kendi hayatlarından vazgeçme ve diğerinin ölümüne engel olmamayı seçmişlerdir. Bu sayede, içinde bulundukları sistemin zalimliğinden dolayı yaşadıkları mağduriyeti, sisteme karşı hissettikleri öfkeyi korumak ve devam ettirmek ve sistemdeki kişilerde aynı çaresizliği ve öfkeyi oluşturmak amacıyla kullanmışlardır. Bu seçim, David'in kurtarma fantezileriyle birlikte ele alındığında, yasaya ve yasa koyuculara karşı bir hamle yapmayı ve bu nedenle yaşayacağı suçluluktan kaçabilmeyi başardığını ve arzuladığı şeye sahip olduğunda değerinin düşmeyeceğinden emin olabildiğini çünkü kendisinin o arzuya ulaştığını görmesini kendi elleriyle engellediğini göstermektedir.

Sonuç olarak, "Ölümle Yaşam Arasında" filminin incelenmesinde, kurtarma fantezisi ve ahlâki mazoşizm ele alınmış; bu iki kavramın narsisizmle ve narsistik ihtiyaçlarla ilişkisi incelenmiştir. Filmde, karakterlerin bu kişilik özelliklerinin gelişiminin dinamik kökenlerine dair herhangi bir bilgi bulunmadığından, bu kökenlere yönelik yorumların incelemenin kapsamının dışında kalacağı düşünülmüş ve bunlara değinilmemiştir. Ancak, David ve Constance'ın farklı nedenlerle benzer psikolojik süreçlerden geçtiği ve birbirlerini tamamlayan bir kararla, hem kendi kurtarma fantezilerini hem de mazoşistik döngülerini destekleyecek bir şekilde davrandıkları, amaçladıkları etkiyi yaratarak ihtiyaç duydukları hazza ve mutluluğa ulaşabildikleri ancak kendi ölümleriyle birlikte, bunu yaşamalarının önüne geçtikleri ve başkalarına bu sayede acı yaşattıkları dikkat çekmiş ve David'in ölüm cezasını almasına yönelik yaptıkları seçimler söz konusu çerçevede incelenmiştir. 


\section{Kaynaklar}

Brown, S. ve Nyswander, M. (1956). The treatment of masochistic adults. American Journal of Orthopsychiatry, 26(2), 351-364.

Cooper, A. M. (1988). The narcissistic-masochistic character. In R. A. Glick \& D. I. Meyers (Eds.), Masochism: Current psychoanalytic perspectives (pp. 117-138). Hillsdale, NJ: The Analytic Press.

Durkin, H. E. (1957). Some techniques for the clinical management of masochism. American Journal of Orthopsychiatry, 27(1), 185-199.

Esman, A. H. (1987). Rescue fantasies. Psychoanalytic Quarterly, 56, 267-270.

Gillman, R. D. (1992). Rescue fantasies and the secret benefactor. Psychoanalytic Study of the Child, 47, 279-298.

Kernberg, O. (2009). The concept of the death drive: A clinical perspective. International Journal of Psychoanalysis, 90, 1009-1023.

McWilliams, N. (2010). Psikanalitik tanı: Klinik süreç içinde kişilik yapısını anlamak (2.Basım). İstanbul: İstanbul Bilgi Üniversitesi Yayınları.

Parker, A. (2003). Ölümle yaşam arasında (The life of David Gale) [Film]. ABD: Universal Pictures.

Sabbadini, A. (2003). 'Not something destroyed but something that is still alive': Amores Perros at the intersection of rescue fantasies. International Journal of Psychoanalysis, 84, 755-764.

Schafer, R. (1984). The pursuit of failure and the idealization of unhappiness. American Psychologist, 39(4), 398-405. 


\section{Summary: \\ The Analysis of 'the Life of David Gale': Rescue Fantasies and Moral Masochism}

The movie "The Life of David Gale" was directed by Alan Parker in 2003. David Gale, the Head of Philosophy Department of the University of Texas and a capital punishment abolitionist, is convicted of murder and rape to his friend, Constance Harraway who is a leader of an organization against the death penalty, and is sentenced to death. Three days before his execution, he requests and conducts an interview with a journalist, Bitsey Bloom, to explain the background of his penalty. However, after the execution was performed, it turns out that Constance committed suicide and the scene was set up in order to demonstrate that death sentences might be unjustly carried out. According to the flashbacks, it is observed that David and Constance have strong 'rescue fantasies' but fail to prevent the execution of several convicts. These fantasies can be regarded as their opposition to the law (and Oedipal father) and include anger as well as guilt, both of which result in self-destructive behaviors and narcissistic breakdown, necessitating a bigger rescuing act. However, their biggest rescue plan involves moral masochistic characteristics because they believe that their suffering will result in a superior goodness, whereas engaging in repetition compulsive behaviors and unconsciously delivering their anger by inducing pain onto others through their death. In the current movie analysis, David and Constance's choice about sacrificing their lives for an ideal is discussed in the light of the related literature on rescue fantasies and moral masochism.

Keywords: Moral masochism, rescue fantasy, narcicism, repetition compulsion. 